Exploring grassroots innovation phenomenon through the lived experience of an Indian grassroots innovator

\author{
Rajul G. Joshi \\ Research Scholar at University of Technology Sydney, Australia \\ Dr. John Chelliah
}

Senior Lecturer in Management, Management Discipline Group, University of Technology

Sydney, Australia

Dr. Veeraraghavan Ramanathan

Director, The B-Smart Consulting Group, Brisbane, Queensland, Australia

Corresponding author:

Rajul G. Joshi can be contacted at: rajul.g.joshi@student.uts.edu.au, joshi.rajul@gmail.com 


\section{Exploring grassroots innovation phenomenon through the lived experience of an Indian grassroots innovator}

\section{Introduction}

Over the past 20 years, grassroots creativity has taken the centre stage in the discourse of sustainable socio-economic development and poverty alleviation in developing countries (Gupta, 1996; Warren, 1990). In practice, grassroots innovation (GI) is referred to as grassroots creativity, comprising of traditional knowledge (TK) and skills, which are translated into innovation by the poor and marginalized people of the rural areas (Gupta, 1996; Letty et al., 2012; Paunov, 2013). Indian GI predominantly uses either TK or involves an adapted use of modern technology that is affordable and convenient to lower-income groups (Gupta, 1996; Jain and Verloop, 2012; Paunov, 2013). Examples of some Indian GIs are: bicycle sprayer, cotton stripping machine, motorcycle-driven plough, and clay refrigerator (NIF 2004-2011). Such innovations are becoming significant source of sustainable solutions for regional growth and development (Seyfang and Smith, 2007; Wamae, 2009). GI is increasingly a sought after knowledge asset in both research and practice (Davies, 2012; Gupta, 2013).

There are many studies that highlight the importance and need for research on GI. For example, Cozzens and Sutz (2012) argue that it is important to focus upon innovations that are from marginalized people and informal economies. Similarly, Erika and Watu (2010) assert that innovation studies in the informal sector have immense potential to contribute to the literature, as the dynamics of this sector are different from the formal sector that currently dominates the literature. Scholars have highlighted the dearth of empirical research on technological niches originating from civil society (Longhurst and Seyfang, 2011; Seyfang and Smith, 2007). These scholars are calling for more research into the current conflicting worlds of market-driven and social driven economies in developing countries.

In South Asian countries such as India, poverty can be a double edged sword providing enormous opportunities but also challenges (Khilji, 2012). India is a lower-middle income country with more than 1.2 billion inhabitants and a GDP per capita of PPP US \$3,703.5 (Dutta, 2012). The latest 2011 census of India shows that $68.84 \%$ of the population live in some 6,38,000 villages (Census of India 2011). People in these areas undertake innovative activities to solve localized problems and they usually work outside formal organizations such as research institutes or business firms (Bhaduri and Kumar, 2011). These are grassroots innovators (GIrs), the majority of whom are illiterate and not formally trained in a technical field, but possess a know-how or ability to innovate with frugal resources (Onwuegbuzie, 2010; Srinivas and Sutz, 2008; Subba Rao, 2006). In order to thrive socially and economically, a developing country such as India must support pro-poor innovation from the grassroots communities (Dutta, 2012; Dutz, 2007) and enhance the GI ecosystem (Pathak, 2008; Gupta, 2013) in a bottom-up manner. Though in recent years India has nurtured the innovation landscape, the ecosystem for individual innovators at the grassroots level is weak which in turn adversely impacts the commercialisation possibilities for GIrs (Gupta, 2013).

Both the GI phenomenon and the aspirations of the individual GIrs have been disregarded by the researchers and policymakers in the innovation field (Dheeraj et al., 2003; Gupta, 2013; Gupta and Sinha, 2002; Pathak, 2008; Rajan, 2012). After examining the motivations of the Indian GIrs, Bhaduri and Kumar (2011) concluded that large numbers of GIrs are driven by intrinsic motivations. Government policies based on extrinsic incentives naturally had adverse effects on GI impacting co-operation with the government as a stakeholder. Current studies relating to challenges in mobilizing and commercializing GI and traditional

\footnotetext{
* The authors would like to thank the editors of SAJGBR and the anonymous reviewers for their valuable comments.
} 
knowledge of India (See for example, Joshi and Chelliah, 2013; Gupta, 2013; De Keersmaecker et al., 2012; Dutz, 2007; Kieff, 2005; Gupta et al., 2003; Dheeraj et al., 2003; Gupta and Sinha, 2002) highlight neoclassical frameworks that focus upon availability of capital, access to markets, labour supply, raw materials and technology.

Overall, GI is an understudied area (De Keersmaecker et al., 2012; Gupta, 2003; Onwuegbuzie, 2010), which is up till now mainly examined from the economical and utilitarian perspective. Rajan (2012), proffers that the prevalent, rational and economic models of competitive innovation for profit are not suitable to study the GI which is based on empathy and social responsibility. This is a promising start, however, based on the extant literature we propose that the phenomenon of GI, especially the ideation, opportunity recognition, prototyping and scaling stage of GI, has not been explored in a systematic manner. The research on GIs in developing countries is still at a nascent stage and there is indeed a need to explore the GI phenomenon through a human science approach. Hence, through this paper, we attempt to fill this existing void in the innovation literature using India as an example of a South Asian nation by exploring GI phenomenon through lived experiences of the grassroots innovator.

We begin with a discussion on existing definition and characteristics of GI, and then utilise three theoretical lens to comprehend the under researched GI phenomenon. Subsequently, we discuss research strategy and the lived experiences of an Indian GIr. Followed by the thematic analysis, interpretation and discussion. Finally, we conclude the paper with a discussion on limitations and agenda for future study.

\section{Grassroots Innovation Definition and Characteristics}

The term 'grassroots' in grassroots innovation (GI) refers to the spatially-constrained activities (Davies, 2012; Seyfang and Smith, 2007). The notion of GI and its importance for India was first emphasised by Mahatma Gandhi. By showcasing the importance of local technologies such as spinning wheel (Charkha), for rural self-reliance (Gram-Swaraj), he initiated the People's Science Movement in India (Abrol, 2004). Then, in the early 1990s, Dr. Anil Gupta emphasised the notion of grassroots creativity and the importance of the knowledge rich poor. The preliminary definition of the term GI in India was coined by him and his Honeybee Network (HBN) which is recognized for mobilising and protecting GI and Traditional Knowledge of India (Cozzens and Sutz, 2012). Overall, in the academic discourse GI is portrayed through varied dimensions such as: grassroots creativity (Gupta, 1996), the grassroots movement or community-led innovations (Seyfang and Smith, 2007), traditional-knowledge based innovations (Dheeraj et al., 2003; Gupta, 1996), rural innovation (Jain and Verloop, 2012; Seyfang and Smith, 2007), empathetic innovation (Gupta, 2010; Rajan, 2012), and informal innovation (Erika and Watu, 2010).

Over the past twenty years there has been a burgeoning interest in pro-poor innovations. Authors like Chataway et al. 2013; Srinivas and Sutz, 2008; Hart and Pahalad, 2002; have developed models of pro-poor products and services in the informal sector. Such pro-poor innovations are further classified as "Bottom of pyramid" innovations (Hart and Pahalad, 2002), "Below the radar innovations" (Kaplinsky et al., 2009) and "Emergent" innovations (Jain and Verloop, 2012). However, currently there is a lack of clarity and consensus about the term GI (De Keersmaecker et al. 2012). Keeping in mind this lack of clarity, we refer to GI as science and technological development at the grassroots leading to a novel product or service that has a tangible socio-economic value. These innovations are mainly conceived and developed through the acumen of the Indian grassroots people for solving the problems faced by their or surrounding local communities.

GI can be classified as pro-poor innovation and is often synonymously related with frugal/bottom-of-pyramid (BoP) innovation in the literature. Although GI shares a close relationship with this innovation, there are fine differences between these innovations as they 
approach grassroots from different perspectives and purposes. For instance, frugal/BoP innovations are defined as low-cost and high-quality products with business-models from emerging markets aimed at creating value for an underserved market (Bhatti, 2012; Radjou et al., 2012; Krishnan, 2010). Here, grassroots people are the target consumers (Bhatti, 2012; Paunov, 2013), and the innovations are conceived and developed by the large corporations or people from non-marginalized sectors with an aim to enhance market reach in developing countries.

On the contrary, GIs are conceived by the GIrs to solve the problems experienced or observed by them, and not for profit or mass consumption. These innovations may not be of the highest quality but are cost efficient (Gupta, 1996; Seyfang and Smith, 2007), affordable and frugal in terms of resource requirements. Additionally, it has the potential to improve local productivity (Pathak, 2008; Dutz, 2007; Cécora, 1999) thereby contributing to regional development (Church, 2005; Cécora, 1999) and social capital at the bottom of the pyramid (Ansari et al., 2012). GI are scarcity-induced innovations (Srinivas and Sutz, 2008) which are mainly conceived to meet a need that is overlooked by the mainstream (Monaghan 2009). Most of this innovation is necessity-led and enhances the livelihood of the grassroots innovators (GIrs) or of the users of GI in the local areas (Pathak, 2008; Rajan, 2012). According to Rajan (2012), a user-driven model based on empathy and social responsibility is imperative for the organization of GI. A unique aspect of GI is that the grassroots people or lower-income people are the providers of innovation and they spearhead innovation development, production and consumption through the support of various institutions such as Non-Governmental Organizations (NGO) or publicly-funded research laboratories (Gupta, 1996). In summary GI is primarily undertaken to solve local problems, empower local people and improve livelihoods and, these objectives differentiate GI from the other closelyassociated innovations such as BoP innovation.

\section{Theoretical Lens}

Seminal work on grassroots activities and marginalized communities is anchored in anthropology, sociology, political science and law. Most of this work relates to a discussion on development, protection, and sustainability. Innovation in the informal setting, especially GI, has received little attention from scholars of management, innovation and development studies (Cozzens and Sutz, 2012). Informal setting relates to the place where the marginalized households and communities stay and undertake set of activities to earn their livelihood. Increasingly, GI is being associated with sustainable livelihood than economic consequences of innovation (Cozzens and Sutz, 2012; Letty et al., 2012). Furthermore, GIrs are not driven solely by commercial motives, but rather they innovate to solve some of the daily problems faced by themselves or their communities, disregarding the prospects for private appropriation or monetary gains (Bhaduri and Kumar, 2011).

Western philosophy is founded on an individual-based rights system, utilitarianism and the commodification of natural resources (Bijoy, 2007). In contrast, GIrs battle with different belief systems, motivations, resource scarcity and conflicting interests (Joshi and Chelliah, 2013; Erika and Watu, 2010). These elements challenge innovation diffusion, determination of Intellectual Property Rights (IPR), benefit-sharing norms, exchange rules, exchange relationships, and the access and use of TK and associated innovations (Joshi and Chelliah, 2013) in the current capitalistic and globalized world. This suggests that economic and monetary factors are not the only key factors in the context of GI.

Utilitarian and rational choice theories have a heavy influence on the concept of innovation. While innovation commercialisation within economics and innovation literature is assumed beneficial, fair and easy, this is not necessarily the experience of those from the grassroots sector. Moreover, the utilitarian approach does not deal with equity and fairness in exchange for goods and benefits (Sunder, 2006). Critics and the vanguard of culture argue 
that the market-approach poses a threat to the social structures and the livelihoods of local people (Vermeylen, 2008). In contrast, some view commercialisation as an act of emancipation and liberation, provided knowledge-holders, innovators and community are involved in the process and are benefiting from the commodification and commercialisation output (Vermeylen, 2007; Vivekanandan et al., 2004; Gupta, 2003; Cécora, 1999;). With a focus on indigenous communities, Busingye and Keim (2009) argue they are not opposed to technological advancement but to the use that is made thereof through the patent rights and the dynamics of the free market. Therefore, there is a necessity to explore the underpinning social, economic, moral exchange dynamics and interpersonal relationship experienced by the GIrs at ideation, opportunity recognition, prototyping and scaling stage of GI.

In order to discern the GI phenomenon and the dynamics of exchanges and interpersonal relationship facilitating, we use three theories: social exchange theory (SET), psychological contract theory (PCT) and diffusion theory. SET enhances the understanding of the individual and inter-personal exchange behaviour of the GIrs. To offset the utilitarian bias of SET and to discern expectations and relationship ideologies influencing the innovation behaviours and actions, we also draw upon PCT. We then use diffusion theory as an overarching theory to provide insights into the contextual factors of social system of innovation leading to social change. Thus, these three theories allow the comprehension of embedded socio-economic exchange dynamics, inter-relationship and expectations, and other contextual factors of the social system of innovation respectively. Individually each theory by itself cannot provide a holistic understanding of the lived experiences of GIrs; therefore the three are used collectively.

\subsection{Social Exchange Theory}

Social Exchange Theory (SET) studies the series of interactions that generate reciprocal obligations. This theory provides insights into the socio-economic behaviours, macro and micro-economic structures. Economists and anthropologists debate the exchange behaviour from rational and relational stances, where the former relates to optimizing behaviour and the latter thinks of exchanges in terms of reciprocating behaviour (Meeker, 1971). In their discussions on anatomy of exchange, Anderson et al., (1999) argue that the objective of exchange defines and directs the relevant exchange network, process and content. SET lens is used in this research to gain an understanding of relational and transactional aspects of the exchange experiences embedded in GI.

SET explains exchanges from utilitarian and behavioural orientations and, how this exchange relationship shapes macro and micro aspects of socio-economic relationship in the society. Further at the micro-level, SET has the potential to provide a unitary framework for a social system as well as the behavioural aspects of actors and their obligatory relationship with other actors. SET is criticized for its over-reliance on utilitarian conceptualization of exchange relationship, generalizing exchange behaviour, undermining the cultural aspects and disregarding the intrinsic aspects of social behaviour. However, the strength of this theory lies in its explanatory power of social and economic relationship. SET also assists in discerning the extrinsic motivations of socio-economic actions of an actor.

\subsection{Psychological Contract Theory (PCT)}

Both classical and contemporary social theorists such as Weber, Mead, Schutz and others have shown that expectations are central to the human agency (Borup et al., 2006). Examination of expectations not only provides insights on the anticipation of the future, but also gives an account of rhetoric of promises, hopes and fears embedded in the tacit contractual relationships (Brown and Michael, 2003). While the traditional economics views expectations from an objective and positivist stance, the science and technology studies take a more constructivist stance. The latter view expectations as performative in attracting the 
interest of necessary allies, (various actors in innovation networks, investors, regulatory actors, users etc.) for defining roles, and building mutually-binding obligations and agendas (Borup et al., 2006). PCT is also very useful in analyzing both the expectations and the outcomes of exchange relationship. The promissory obligation dimensions of the psychological contract provide insights into the cognitive implications of contracting at the individual level (Thompson and Hart, 2006).

Psychological contracts are beliefs or perceptions that are ongoing, dynamic and implicit in human nature, based on the principle of reciprocity and exchange. Psychological contracts that are primarily driven by the economic exchange are transactional in nature, whereas those driven by socio-emotional aspects are relational in nature, and the exchanges that are driven by principle or cause, not limited to self-interest, are ideological in nature (Salicru and Chelliah 2014; Thompson and Bunderson, 2003). It is therefore a useful guide for contractarian ethics (Donaldson and Dunfee, 1994) which is also central to the literature of grassroots communities being exploited under the neoclassical and utilitarian approach. Taking these aspects of PCT, we attempt to discern the intrinsic aspects of the individual's reciprocal relationship at the interpersonal level.

\subsection{Diffusion Theory}

Diffusion theory is integral in social sciences and innovation studies because it provides an understanding of the process of social change. Until 1969, the tradition of diffusion research was mainly in the field of rural sociology. Since then it has increasingly become interdisciplinary. Diffusion theory explains how over period, new ideas, beliefs, knowledge, practices, programs, and technologies diffuse and subsequently are adopted through various social system channels. A social system is 'a set of interrelated units that are engaged in joint problem solving to accomplish a common goal' (Rogers 2003, p. 23). Diffusion is the process by which an innovation is communicated through certain channels over a period among the members of a social system (Rogers, 2003). The GIrs work with varied agencies to develop and diffuse innovation for commercial purpose. For the purpose of this research, diffusion theory is useful for understanding the social system that facilitates ideation, opportunity recognition and scaling of GI, and the contextual factors embedded in the process of social change.

Against the backdrop of these three theories, we then attempt to gain an appreciation for the economic, moral, personal and social elements that underpin lived experiences at different stages of GI. Figure I pictorially presents the concepts and theories that guide this research. Deeper insights into the innovation experiences of the GIrs are gained by exploring the narratives of individuals and exploring their circumstances (Creswell and Miller, 2000; Schipper, 1999). We have anchored our interpretation on broad elements to understand the lived experiences of the GI phenomenon. These broad elements - personal, economic, moral and social, are intertwined with the actor (GIr) their actions (GIs) and their interplay (exchange relationship and expectations) which facilitate GI. Here, the personal elements mainly relate to the individual's identity, capability and attitude while moral elements constitute the belief system of rights, duty and responsibility influencing the individual. Overall, sources for the GIrs' lived experiences are the everyday experiences of innovators, their background and their interaction with the environment for opportunity recognition, ideation, prototyping and scaling of GI. 


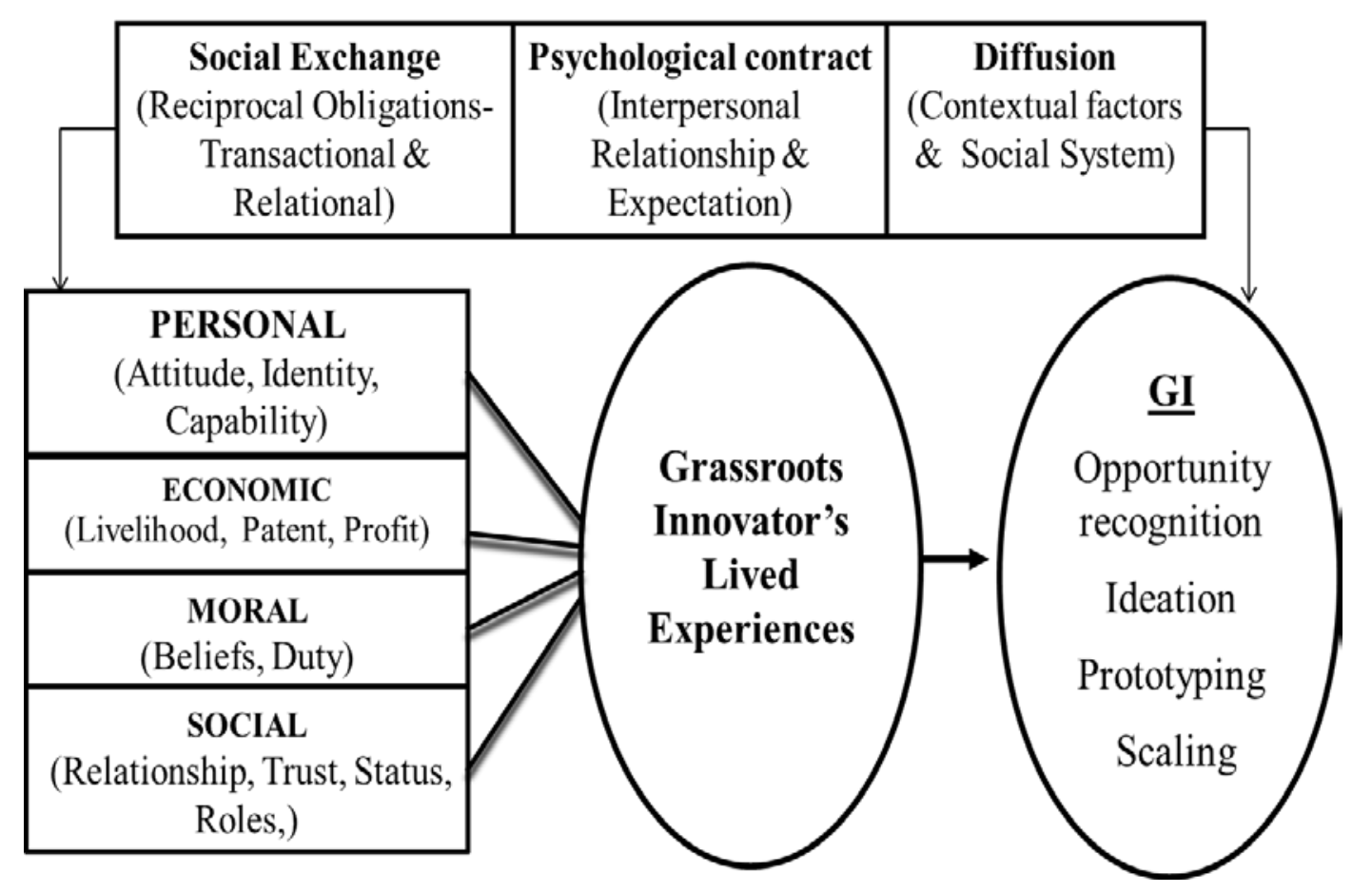

FIGURE I: Concepts and Theory

\section{Research Strategy}

Anchored in the phenomenological form of inquiry, this study proposes a constructivist episteme and interpretive stance, to explore the GI phenomenon. The phenomenological research tradition provides a description (the what) of the experience rather than explanations (the why) of the experience and also bring to light the meaning that the individuals derive from their experiences (Van Manen, 1990). Lived experience provides a first-hand account of the phenomenon and therefore, it is an important aspect in the phenomenological study. Experiences are fluid in nature and cannot be examined through an objective lens; nevertheless, hermeneutic phenomenology seeks to bring the essence of a lived experience an interpretive descriptive text that acknowledges the complexity of the experiences (Van Manen, 1990). Lived experiences are interpreted using hermeneutics, which allows interpretation and articulation of how practitioners or the person-in-context made sense of their lived experiences. Overall, our research design and analysis is guided by the key hermeneutic phenomenology principles proposed by Van Manen because it allows the investigation of the interpretive structures of experience, which is most appropriate for analyzing qualitative data and adding rigor to the overall investigation.

To comprehend the data-set, we began with the initial scanning and interpretation of the lived experiences shared by the GIr. Van Manen (1990) terms this process as 'immersion' into data and this process is very important as it not only provides 'sense' of the data collected but it also facilitates coding. The dataset were organized into text after iterative reading of the text. Simultaneously, preliminary interpretation was undertaken which facilitated understanding of the text and coding. Whilst, the first order of respondent's constructs were identified through thematic analysis and preparing the list of phrases used by the respondent, the detailed description of the setting, participant and the themes was given. Such, thick descriptions not only allowed us to reflect the relationship with the themes. It also provided credibility to the data collected and gave contextual understanding of the applicability of the finding too (Creswell and Miller 2000). Lastly, we synthesized the themes through connecting strategy on linking the literature to the themes identified and reconstructing interpretations into the life story of the GIr. 
A lived experience of a GIr whose innovation was a cotton stripping machine is discussed in the subsequent section. Data was collected through purposive sampling as the research required a participant who had experienced the phenomenon that is being investigated. Access for interviewing the GIr was provided by the National Innovation Foundation (NIF), an autonomous body of the Department of Science and Technology, Government of India, whose stated aim is to recognize, respect and reward grassroots technological innovators and traditional knowledge holders. One and a half hour long open-ended interview with the GIr allowed gathering the lived experiences and innovators' reflections on the phenomenon. Subsequently, a half hour interaction with the GIr was arranged for member checking and validation. In addition, a field visit to this innovator's house as well as factory and ginning site provided more insights on the GI phenomenon. Here, Seidman's (1998) approach to phenomenological interviewing was followed. This approach allows a more in-depth access to the participant's experience and an opportunity to reflect more closely on the meaning and essence of the experiences of the phenomenon investigated. In phenomenology, the focus is not on the world but rather it is on the respondent who experiences the world. Hence, it is important to know how the respondent experienced the world, or any particular issue or situation..

\section{Lived Experience}

A farmer's son and $9^{\text {th }}$ grade school dropout is recognised today as a successful grassroots innovator and a rural entrepreneur. He grew up in a small village of India named 'Trant', which is in the Viramgam province of Ahmadabad district of Gujarat State. He has four brothers and four sisters. Their source of livelihood is agriculture. Due to poverty he could not continue his education and at a very tender age, had to work on farms and do cotton lint stripping. Later, he repaired farm equipment, along with house wiring, radio and clock repair. $\mathrm{He}$ is from a Patel community which is predominantly involved with agriculture. In their community, boys and girls get married very early. He got married at the age of 18 and he has two sons and four grandchildren and they all live together.

As a child, he was fascinated by the tractor and used to observe the mechanism of tractors for hours. He is still passionate about mechanical field and loves observing and understanding the technicalities of all types of machines. From childhood, he also witnessed that women and children of his village undertook the arduous task of stripping cotton lint from the cotton shell. He experienced and observed the negative impact of this job-work on the socio-economic life of the village people and farmers. It was affecting the studies of the children as majority of them had to discontinue studies to spare time for this job work and help their family with their income. Women were also involved in this job-work it was affecting them as they had to balance their household chores, social responsibilities and providing cotton lint on time to the ginners. Further, the quality of cotton lint degrades if it is not removed from the shell in timely manner. Experiencing and witnessing all these issues and challenges, he decided to mechanise this process, help the farmers, women and children, and thereby raise the education level of children in his village. In his late forties, he made a cotton-stripping machine that proved to be beneficial to all the stakeholders in the value chain of the cotton industry.

He faced many trials and tribulations in his innovation journey but he never gave up. It took eight years for him to successfully build an improvised model. In these eight years he developed seven different models. At the ideation stage, he discussed his idea with two of his friends who also helped him with the seed finance for building the prototype. He developed the first prototype in 1991 and demonstrated it to his village people. Many farmers appreciated his work. With this first prototype, he observed that the wastage was more than expected and as a result he was not happy with his efforts. He then worked on developing the second prototype from 1991-1992, and demonstrated it in 1992 to the business communities 
and farmers. He received orders for 50 machines along with the deposit monies. He sold 25 machines in that year, but in 1993, buyers started complaining about the faults in the machine and the quality of cotton. He had to return money to the buyers and to his friends who provided initial financial assistance for pursuing his dream of making cotton stripping machine. All these issues posed a huge challenge for this innovator and he incurred debt of approximately US\$40,600. In spite of these initial failures, he did not despair and continued to develop another improvised prototype. He also trained and engaged his two sons on a fulltime basis for this innovation. To repay the debt he started working at the factory and did jobwork of stripping cotton lint using his old machine. From this setback he realized the importance of raw material and quality testing prior to demonstrating to potential customers and booking orders. With financial support from the Government of India and technical support from National Institute of Design and Indian Institute of Technology, Mumbai he developed an improvised prototype in 1995. This machine was patented with support from Society for Research and Initiatives for Sustainable Technologies and Institutions (SRISTI) and the Western Centre of Grassroots Innovation Augmentation Network (GIAN). He received a national award for this innovation.

This farmer's son metamorphosed into a successful grassroots innovator and rural entrepreneur who now manufactures and distributes his machines under the banner of his own company. He promotes his innovation through advertisements in trade journals, the network of GIrs and by word of mouth. Presently, he also serves as a board member of SRISTI and GIAN. At the age of 63, he is still a curious innovator, showing keen interest in the new field like microprocessor and passionate to nurture younger people to pursue innovation.

\section{Thematic Analysis and Interpretation}

\subsection{Exchange dynamics and Interpersonal Relationship}

Money is an important resource for developing innovation but other non-monetary resources are equally important at the ideation, opportunity recognition, prototyping and scaling stage of GI. Our GIr received monetary and non-monetary resources from friends and family members. Later, the non-monetary help in form of networks, reward in the form of recognition, and design assistance were received from the institutions working for GIs in India. This GIr had experienced both the transactional and relational exchange relationship. Here, the exchanges are driven by the core value system of the innovator and bear cultural influences of collectivist society. For instance, the innovator refrained from taking financial help during his difficult times, rather he devised strategies such as taking up work using his machine, continuing his job and also involving his sons to look after the innovations. It is also evident that a sense of responsibility, reciprocity, attitude and the background of the GIr influences socio-economic exchange decisions to facilitate GI development.

Relational continuity depends on expectation and reciprocal obligation formation (Heide and Miner, 1992; Kaufmann and Stern, 1988). The reciprocal obligations can be substantiated through the arrangements for sale of machine, purchase order, technological, financial and design help, operational help from sons and advice from friends and farmers, and assistance in patent filing. Here the desire to succeed in innovation, and to maintain the status and goodwill, has influenced interpersonal relationship involved in developing and scaling GI. For instance, our GIr's firm has earned goodwill in the cotton industry across India. He feels proud to be an innovator, a businessman and to be on the advisory board of GIAN \& SRISTI. He is satisfied with his GI journey and now wants to act as a beacon for aspiring GIrs and also ready to employ those seeking job. The feeling of gratitude for the support given further shapes the obligatory relationships. Overall, it could be construed that trust, risk, role and personal values play an important role in decision making related to social and economic exchanges. This facilitates GIrs in their GI development journey. 
Our GIr is a recipient of the national award for GI (NIF 2004-2011), and he is happy to have received support for the protection of his intellectual property. He was not very vocal about his views on patent and he maintained silence when asked about patent in general. According to him, "there is so much to tell and so much that should not be told, and certain things one has to overlook for peaceful life." Recognition, reward and relationship have emerged as an important aspect of exchange dynamics - the key impetus in scaling GI.

Overall, it can be said that all the exchanges - transactional or relational, economic, socioemotional and ideological, are embedded in ideation, opportunity recognition, prototyping and scaling of GI. The following statements reflect exchange dynamics and interpersonal relationships embedded in GI.

\footnotetext{
"I had immense family support .My children; my wife and my brother-in-law helped me in my innovation".

"...So again from 1991 to 1992 I spent time in making a prototype. After making this, we demonstrated this to business community and asked them to support financially. Money was a very important thing as I did not have money at that time."
}

"In 1993 I faced loss huge loss and the sole responsibility of this loss was mine. ...I had to take my elder son in my business and for this he had to sacrifice his college education. I used to go for job and hence, placed both my sons into innovation. I gave them direction and they used to work accordingly. Due to this loss people started avoiding us. I was in debt and was bankrupt and no one stands with the bankrupt or debtor.... However, because of my values I never asked for money from any one. During this time, I used to do job-work with our old machine. The money I used to get from this job-work of dishevelling cotton balls was invested in innovation."

"The chance meeting with SRISTI, NIF and GIAN is the only support that is ongoing,...I would support anyone who would like to work at our factory or anyone interested in innovation. I am a board member of GIAN and SRISTI. I go and attend the meeting and workshops"

“...exchange relationships are situational and related to time and other personal factors."

\subsection{Background and Capabilities}

When interpreting this GIr's reflection on his background and capabilities, it can be stated that 'capability' is the major underlying force influencing the GIr as a social actor in operationalising the GI at each stage. The life story of the GIr draws insights into his capabilities to translate, his experience and an observation into innovation. This capability not only influences ideation and opportunity recognition, but also influences the GIr as an evolving actor in the social system of innovation. Moreover, on-the-job training and experience has helped the innovator understand the importance of quality and service which has led him to excel in his innovation. This lived experience of a GIr demonstrates the acumen and the innate motivation of the innovator to provide a solution to the problem he envisaged in his environment, his ability to multitask and solve a problem. At a later stage, his capability to translate learning into practice has helped the GIr to earn goodwill as an entrepreneur. He is cognizant and aware of the risk involved in GI journey.

This case illustrates that GIrs can succeed by utilising their traditional knowledge/practices, own experience and available resources even if they did not have access to formal education (Agarwal, 1983; Gupta, 1996; Gupta et al., 2003; Onwuegbuzie, 2010). Our GIr was a farmer's son who lacks formal education but has become a businessman and board member of an organisation GIAN and SRISTI (which helped him in securing IPR protection). Overall, social roles, status, and occupation of individuals shape the identity and expectations of an innovator (Cécora, 1999). For instance, the fear of 
accumulating debt and facing the society, forced the innovator to look for an alternative way of handling socio-economic recourses. Such personal and interpersonal elements are an integral part of the GI that provides an insight into the innate aspirations and fears of the GIr.

"My main livelihood is based on agriculture. I had been working since childhood and I had to leave studies. I started off with house wiring, radio repairing, and clock repairing work. ... Since childhood I had mechanical mind... Though we are farmers, we all undertake farm machinery fixing and welding work"

"Observation is a very important thing. Since childhood I have an attitude of observation. When we got the tractor in our village then I used to watch the tractor for hours. Even today, though I am not educated, I can still work in microprocessor related field".

"I am an innovator for sure. I believe that one should have mastery in all work and should have a firm belief that they can do any work."

"When I was working in the ginning factory, I used to sit with the people there and the business community. I had this in my mind that if there was a machine for opening these cotton balls (kaala) then it can be useful and beneficial in many ways."

"As I was maintenance in-charge, I know the importance of service. Service is an important thing. Any ginner whose machine is not working is incurring loss and I can understand this and see this as not their loss but my loss and make sure that this does not happen to them. ...We qive huqe importance to service. Till date we emphasize on 'Must be serviced'",.

\subsection{Challenges in GI and Purpose}

Our GIr reflected on different types of challenges that he faced during the innovation journey and also suggested approaches to facing such challenges. Despite the challenges and trials in ideation and development of GI, it brought positive change in the life of this GIr and opened up an avenue for rural entrepreneurship and socio-economic well-being, thereby adding to inclusive development. The cotton stripping machine has not only introduced new process or system in the ginning industry but also ushered in socio-economic change. We also gathered that the cotton stripping machine not only mechanised the process but also brought in the social change in the community, process change in the industry and life-style change for the GIr and other members of the community. This is substantiated by Cécora (1999) who points out that an individual is a multidimensional social actor and not simply an atomized, utility-optimizing, and interchangeable economic actor. It can be, therefore, asserted that GIs are pro-poor and integral for inclusive growth (George et.al. 2012).

In the course of discussing benefits and disadvantages of his innovation, this GIr noted that one major disadvantage was the job losses that resulted from the mechanisation brought about by his innovation. However, he pointed out that this has been more than offset by a bigger socio-economic gain that he foresaw at ideation stage. His lived experiences of the challenges he faced during ideation and prototyping is insightful and the same is reflected below. 
"... two benefits were, one fast processing for the ginners and second, fast recovery for both the ginners and the farmers. The biggest disadvantage was that the means to livelihood for many was stolen due to this machine, but the exploitation of the children whose education used to get stalled due to this job-work stopped completely. Enabling children to continue education and allow them to study was the biggest purpose behind my innovation and this purpose was met”.

"No innovation is without challenges or problems. One got to face these changes, solve these problems and make their innovation marketable. There are technical, financial, and mental and worker related challenges in an innovation. An innovator has to face all these challenges and should be open to suggestion and advice. In addition to this there are some challenges from the nature or environment."

"...there are instances of fights at home due to innovations. My wife complained that children will turn into beggars because of my aim to innovate, but such situations unfold as per the time and it fades off too."

"Innovation has ushered change in our lifestyle. We were farmer's son, but now we are businessman. I did not study, I had to stop my son's studies, but today my grand children are studying."

"The critical period for us was from 1993 to 2000. The 7 years of hardship were too much. Only an innovator has to bear this pain of struggle"

\section{Discussion and Implications}

Based on the above thematic analysis and interpretation of the lived experience, we suggest that the relational exchanges drives GI. Further, it ushers in long-term personal and socialeconomic change in the life of this GIr. The exchange dynamics embedded in the GIr's lived experience reflects Meeker's (1971) relational exchange rules - reciprocity, rationality, altruism, group gain, and status consistency. Overall, it is observed that GI is driven by economic, socio-emotional and ideological exchange which pivots on reciprocal obligations, rewards, resources, rights and rules.

Capability and acumen with innate sense of socio-economic responsibility drives the GIr. It is evident from the lived experience excerpts that in initiating and exercising control over the innovation process, the role of a local individual or community is very significant (Letty et al., 2012). Hence, we propose that GI is (1) a mind-set driven phenomenon where acumen, capability and belief system of the individual innovator plays an important role, (2) a solution science that enhances livelihood or existing process or product for the greater-good of the community, and (3) driven by trust and reciprocity.

During the course of diffusion of innovation by farmers, Rogers (2003) noted that though economic factors are important, there were other relational aspects such as personal network and word-of mouth promotion which also spreads innovation. Likewise, Agarwal (1983) posits that the contextual aspects of innovation such as economical, technical and social set the scene for diffusion of innovation. All these contextual elements were present in the prototyping and the diffusion of the cotton stripping innovation. For instance, the innovation benefits were communicated through word of mouth and later the GIr started networking with the business and farming communities.

Generally, commercialization is assumed to be challenging for the GIr (De Keersmaecker et al. 2012; Dheeraj et al., 2003), however, this case posits that even ideation is equally 
challenging for the GIr. Here it is also observed that prior to prototyping and commercialisation, GIr goes through many trials and tribulations at the ideation and prototype development stage, facing multiple emotional, economic and moral even with family and network support. The lived experience of GIr has also revealed that GI journey starts off in a lonely and isolated fashion situated in a remote village. Therefore, there is a need for three types of connections, that is rural to rural, rural to urban and GIr to GIr. Such connections will foster the sharing of knowledge and aspirations at an early stage of GI. It lays the ground for relational continuity and socio-economic engagement through cooperative mechanisms. This cooperation can compensate the lack of formal training and the GIr can access timely assistance at the ideation, opportunity recognition and prototype development stage, alleviating the social and emotional pressures. The ecology of GI is founded on bottom-up participation and cooperation in knowledge sharing, innovation development and business skills.

\section{Conclusion}

Overall, this paper uses human science research approach for studying the subjective reality embedded in the GI phenomenon. Through this approach we were able to provide richer understanding of the underlying individual and interpersonal dynamics shaping the GI. This approach assists in explaining the essence of the GI phenomena. In addition, application of hermeneutic phenomenology to pro-poor innovation research and practice is an area ripe for future studies. This may serve as an aid for future research on scaling, managing GI, and developing entrepreneurial capabilities of the grassroots innovators.

The study confirms that no single theory can fully explain the lived experiences of the GIrs at the ideation, opportunity recognition, prototyping and scaling stage of GI. Rather, integrated theoretical perspectives are needed. Therefore, the three anchoring theories diffusion, social exchange and psychological contracts are used as they have relevance with all aspects of the lived experience of the GIr. These theories provided a lens to understand the challenges at the four stages of GI. Firstly, the diffusion lens was useful for understanding the contextual factors such as role of GIr and other actors, and communication of GI outcomes at each stage. Secondly, the social exchange lens allowed consideration of explicit socio-economic reciprocal obligations dynamics encompassing exchange objectives and which facilitates GI at varied stages. Finally, psychological contract, shed light on the innate aspects of implicit exchange relationships and expectations embedded in such relationships.

\section{Limitations and Agenda for Future Study}

Obviously as an exploratory study of one GIr, this paper's main limitation is the question of whether the findings can be generalised in a wider context. While, we acknowledge this limitation, the purpose of this study is not to generalise the findings but rather provide a contextual understanding of what constitutes the lived experiences of GI. We recommend that a future study covering greater number of GIrs across India be undertaken to gain a better appreciation of the bigger picture. Further research is needed to extend these findings, explore GI phenomenon in other South Asian countries and to examine the role of expectations in GI dynamics. This paper also serves as a prologue for the future research on innovation and entrepreneurship for economically deprived and marginalised grassroots people. In sum, this research would be of interest to researchers, practitioners, activists and policymakers in the field of regional and inclusive development, and innovation and management studies. 


\section{REFERENCES:}

Abrol, D. (2004). Lessons from the design of innovation systems for rural industrial clusters in India. Asian Journal of Technology Innovation, Vol. 12, No. 2, 67-97.

Agarwal, B. (1983), 'Diffusion of rural innovations: some analytical issues and the case of wood-burning stoves', World Development, Vol. 11, No. 4, pp. 359-76.

Anderson, W.T., Challagalla, G.N. \& McFarland, R.G. (1999), 'Anatomy of exchange', Journal of Marketing Theory and Practice, pp. 8-19.

Ansari, S., Munir, K. \& Gregg, T. (2012), 'Impact at the 'bottom of the pyramid': the role of social capital in capability development and community empowerment', Journal of Management Studies, Vol. 49, No. 4, pp. 813-42.

Bhaduri, S. \& Kumar, H. (2011), 'Extrinsic and intrinsic motivations to innovate: tracing the motivation of 'grassroot'innovators in India', Mind \& Society, Vol. 10, No. 1, pp. 2755.

Bhatti, Y. (2012), 'What is Frugal, What is Innovation? Towards a Theory of Frugal Innovation', Towards a Theory of Frugal Innovation (February 01, 2012).

Bijoy, C. (2007), 'Access and Benefit-Sharing from the Indigenous Peoples' Perspective: The TBGRI-Kani 'Model,', Law, Environment and Development Journal, Vol. 3, No. 1, p. 18.

Borup, M., Brown, N., Konrad, K. \& Van Lente, H. (2006), 'The sociology of expectations in science and technology', Technology Analysis \& Strategic Management, Vol. 18, No. 3-4, pp. 285-98.

Brown, N. \& Michael, M. (2003), 'A Sociology of Expectations: Retrospecting Prospects and Prospecting Retrospects', Technology Analysis \& Strategic Management, Vol. 15, No. 1, pp. 3-18.

Busingye, J., \& Keim, W. (2009). The political battlefield: negotiating space to protect indigenous and traditional knowledge under capitalism. International Social Science Journal, Vol. 60, No. 195, 37-54.

Cécora, J. (1999), Cultivating grass-roots for regional development in a globalising economy: innovation and entrepreneurship in organised markets, Ashgate Publishing Ltd.

Chataway, J., Hanlin, R., \& Kaplinsky, R. (2014). Inclusive innovation: architecture for policy development. Innovation and Development, Vol. 4, No. 1, 33-54.

Church, C. 2005, 'Sustainability: The Importance of Grassroots Initiatives, paper presented at Grassroots Innovations for Sustainable Development Conference, UCL, London, 10 June', UCL, London, Vol. 10

Census of India, (2011), Office of the Registrar General and Census Commissioner, India, New Delhi. <http://censusindia.gov.in/>

Cozzens, S. \& Sutz, J. (2012), Innovation in Informal Settings: A Research Agenda, unpublished manuscript.

Creswell, J.W. \& Miller, D.L. (2000), 'Determining validity in qualitative inquiry', Theory into practice, Vol. 39, No. 3, pp. 124-30.

Davies, A. (2012), Enterprising Communities: Grassroots Sustainability Innovations, Vol. 9, Emerald Group Publishing.

De Keersmaecker, A., Parmar, V., Kandachar, P. \& Baelus, C. (2012), 'Towards scaling up grassroots innovations in India: A preliminary framework'.

Dheeraj, A., Basant, R. \& Gupta, V. (2003), Commercialization of Traditional Knowledge Based Technologies by Small Entrepreneurs: An Exploration of Strategic and Policy Options, Working paper (No. WP2003-03-03), Indian Institute of Management Ahmedabad, Research and Publication Department. 
Donaldson, T. \& Dunfee, T.W. (1994), 'Toward a unified conception of business ethics: Integrative', The Academy of Management Review, Vol. 19, No. 2, pp. 252.

Dutta, S. (2012), 'The Global Innovation Index 2012', INSEAD, Fontainebleau.

Dutz, M. A. (Ed.). (2007). Unleashing India's innovation: towards sustainable and inclusive growth. World Bank Publications.

Erika, K.-M. \& Watu, W. (2010), Innovation and the development Agenda, Organization for Economic.

George, G., McGahan, A.M. \& Prabhu, J. (2012), 'Innovation for inclusive growth: towards a theoretical framework and a research agenda', Journal of Management Studies, Vol. 49, No. 4, pp. 661-83.

Gupta, A.K. (1996), 'Getting Creative Individuals and Communities Their Due: A Framework for Operationalizing Article $8 \mathrm{~J}$ and $10 \mathrm{C}$, Paper presented to CBD secretariat. Ahmedabad: Society for Research and Initiatives for Sustainable Technologies and Institutions. Mimeo.

Gupta, A.K. (2003), 'Conserving biodiversity and rewarding associated knowledge and innovation systems: Honey Bee perspective', Intellectual property: trade, competition, and sustainable development, Vol. 3, p. 373.

Gupta, A.K. (2010), Empathetic innovations: Connections across boundaries, Indian Institute of Management., Ahemadabad.

Gupta, A.K. (2013), Policy gaps for promoting green grassroots innovations and traditional knowledge in developing countries: learning from Indian experience, Indian Institute of Management Ahmedabad, Research and Publication Department.

Gupta, A.K. \& Sinha, R. (2002), 'Contested Domains, Fragmented Spaces: rights, responsibilities and rewards for conserving biodiversity and associated knowledge systems', Traditional ecological knowledge for managing biosphere reserves in South and Central Asia, pp. 161-81.

Gupta, A.K., Sinha, R., Koradia, D., Patel, R., Parmar, M., Rohit, P., Patel, H., Patel, K., Chand, V. \& James, T. (2003), 'Mobilizing grassroots' technological innovations and traditional knowledge, values and institutions: articulating social and ethical capital', Futures, Vol. 35, No. 9, pp. 975-87.

Hart, S., \& Prahalad, C. K. (2002). The Fortune at the Bottom of the Pyramid. Strategy+ Business, 26, 54-67.

Heide, J.B. \& Miner, A.S. (1992), 'The Shadow Of The Future: Effects Of Anticipated Interaction and Frequency Of contact On Buyer-Seller Cooperation', Academy of management journal, Vol. 35, No. 2, pp. 265-91

Hofstede, G., Hofstede, G.J. \& Minkov, M. (2010), Cultures and Organizations: Software of the Mind, revised and expanded 3rd ed, McGraw-Hill, New York, NY.

Jain, A. \& Verloop, J. (2012), 'Repositioning grassroots innovation in India's S\&T policy: from divider to provider', Current Science (00113891), Vol. 103, No. 3, pp. 282-5.

Joshi, R.G. \& Chelliah, D.J. (2013), 'Sharing the Benefits of Commercialisation of Traditional Knowledge: What are the Key Success Factors?' The Intellectual Property Forum, No. 93.

Kaufmann, P.J. \& Stern, L.W. (1988), 'Relational exchange norms, perceptions of unfairness, and retained hostility in commercial litigation', Journal of Conflict Resolution, vol. 32, no. 3, pp. 534-52. Busingye, J. \& Keim, W. 2009, 'The political battlefield: negotiating space to protect indigenous and traditional knowledge under capitalism', International Social Science Journal, Vol. 60, No. 195, pp. 37-54.

Kaplinsky, R., Chataway, J., Clark, N., Hanlin, R., Kale, D., Muraguri, L., ... \& Wamae, W. (2009). Below the radar: what does innovation in emerging economies have to offer other low-income economies?. International Journal of Technology Management \& Sustainable Development, Vol. 8, No. 3, 177-197. 
Khilji, S.E. (2012), 'Editor's perspective: does South Asia matter? Rethinking South Asia as relevant in international business research', South Asian Journal of Global Business Research, Vol. 1, No. 1, pp. 8-21.

Kieff, F. S. (2005). IP Transactions: On the Theory \& Practice of Commercializing Innovation. Stanford Law and Economics Olin Working Paper No. 311. Available at SSRN: http://ssrn.com/abstract $=821327$

Krishnan, R. (2010), 'From Jugaad to systematic innovation', Bangalore: Utpreraka Foundation.

Letty, B. Shezi, Z. and Mudhara, M. (2012) 'An exploration of agricultural grassroots innovation in South Africa and implications for innovation indicator development' UNU-MERIT Working Paper 23.

Longhurst, N. \& Seyfang, G. (2011), 'Harnessing grassroots innovations: Complementary currencies and sustainability', International Event on Community and Complementary Currencies, Lyon.

Meeker, B.F. (1971), 'Decisions and exchange', American Sociological Review, pp. 485-95.

Monaghan, A. (2009), 'Conceptual niche management of grassroots innovation for sustainability: The case of body disposal practices in the UK', Technological Forecasting and Social Change, Vol. 76, No. 8, pp. 1026-43.

NIF (2004-2011), National Innovation Foundation, National Innovation Foundation, India, viewed January 20, 2013, <http://www.nif.org.in/>.

Onwuegbuzie, H. (2010), 'Sustainable Development Strategy Using Indigenous Knowledge and Entrepreneurship', Available at SSRN 1841787.

Pathak, R. (2008), 'Grass-root creativity, innovation, entrepreneurialism and poverty reduction', International Journal of Entrepreneurship and Innovation Management, Vol. 8, No. 1, pp. 87-98.

Paunov, C. (2013), Innovation and Inclusive Development: A Discussion Of The Main Policy Issues, Organisation for Economic Cooperation and Development (OECD), Paris, France, Paris.

Radjou, N., Prabhu, J. \& Ahuja, S. (2012), Jugaad innovation: think frugal, be flexible, generate breakthrough growth, Jossey-Bass, San Francisco, CA

Rajan, P. (2012) Organizing grassroots innovations: Examining knowledge creation and sharing practices for technological innovation at the grassroots, Purdue University, Accessed on November 05, 2013: docs.lib.purdue.edu.

Rogers, E.M. (2003), Diffusion of innovations, Free Press, New York

Salicru, S. and Chelliah J. (2014). 'Messing with corporate heads? Psychological contracts and leadership integrity', Journal of Business Strategy Vol.35,No.4, pp.38-46.

Schipper, F. (1999), 'Phenomenology and the reflective practitioner', Management Learning, Vol. 30, No. 4, pp. 473-85.

Seidman, I. (1998), 'Interviewing as Qualitative Research. 2nd', New York: Teachers.

Seyfang, G. \& Smith, A. (2007), 'Grassroots innovations for sustainable development: Towards a new research and policy agenda', Environmental Politics, Vol. 16, No. 4, pp. 584-603.

Srinivas, S. \& Sutz, J. (2008), 'Developing countries and innovation: Searching for a new analytical approach', Technology in Society, Vol. 30, No. 2, pp. 129-40.

Subba Rao, S. (2006), 'Indigenous knowledge organization: An Indian scenario', International Journal of Information Management, Vol. 26, No. 3, pp. 224-33.

Sunder, M. 2006, 'Ip', Stanford Law Review, pp. 257-332.

Thompson, J.A. \& Bunderson, J.S. (2003), 'Violations of principle: Ideological currency in the psychological contract', Academy of Management Review, Vol. 28, No. 4, pp. 57186. 
Thompson, J.A. \& Hart, D.W. (2006), 'Psychological contracts: A nano-level perspective on social contract theory', Journal of Business Ethics, Vol. 68, No. 3, pp. 229-41.

Van Manen, M. (1990), Researching lived experience: Human science for an action sensitive pedagogy, Sunny Press.

Vermeylen, S. (2007), 'Contextualizing 'Fair' and 'Equitable : The San's reflections on the Hoodia benefit-sharing agreement', Local Environment, Vol. 12, pp. 423-36.

Vermeylen, S. (2008), 'From life force to slimming aid: Exploring views on the commodification of traditional medicinal knowledge', Applied Geography, Vol. 28, No. 3, pp. 224-35.

Vivekanandan, P., Prakash, T., James, P., Patel, R., Verma, S.R., Sahu, B., Patel, H., Miglani, K.J., Sinha, R. \& Gupta, A.K. (2004), 'Protecting Traditional Knowledge of small, scattered and disadvantaged grassroots innovators and traditional knowledge holders: Honey Bee perspective: Agenda for Policy and Institutional Change', pp. 4-6.

Wamae, W. (2009), 'Enhancing the role of knowledge and innovation for development', International Journal of Technology Management \& Sustainable Development, Vol. 8, No. 3, pp. 199-220.

Warren, D.M. (1990), Using indigenous knowledge in agricultural development, World Bank, Washington DC. 